assessments and regulatory advice and may indicate that current levels of MPB in formulations are acceptable for young children.

\section{0-107 PROSPECTIVE VALIDATION OF A MODEL-BASED DOSING REGIMEN FOR AMIKACIN IN PRETERM AND TERM NEONATES}

${ }^{1} \mathrm{~A}$ Smits, ${ }^{2} \mathrm{RFW}$ De Cock, ${ }^{1} \mathrm{~K}$ Allegaert, ${ }^{1} \mathrm{~S}$ Vanhaesebrouck, ${ }^{2} \mathrm{M}$ Danhof, ${ }^{2} \mathrm{CAJ}$ Knibbe ${ }^{1}$ Neonatal Intensive Care Unit, UZ Leuven, Leuven, Belgium; ${ }^{2}$ Division of Pharmacology LACDR, Leiden University, Leiden, Netherlands

\subsection{6/archdischild-2014-307384.174}

Background and aims An essential step in drug dosing optimalisation is prospective validation of newly proposed dosing regimens. Based on a recently published population pharmacokinetic (PK) model, a neonatal amikacin dosing regimen was developed. The aim of the current study was to prospectively validate this model-derived dosing regimen.

Methods Routine amikacin therapeutic drug monitoring (TDM) concentrations were prospectively collected. To test efficacy of the dosing regimen, early observed TDM results (i.e. prior to and $1 \mathrm{~h}$ after the second intravenous amikacin dose) reaching target concentrations (trough $<3 \mathrm{mg} / \mathrm{L}$, peak $>24 \mathrm{mg} / \mathrm{L}$ ) were defined. To test stability and accuracy of the model, all observed concentrations were compared with the predicted concentrations and a normalised prediction distribution error (NPDE) was performed. Monte Carlo simulations were used to evaluate amikacin exposure.

Results In total, 1195 TDM results of 579 neonates [median gestational age 34 (range 24-41) weeks, postnatal age 2 (range 1-30) days] were included. Sixty percent of the early trough levels was below $3 \mathrm{mg} / \mathrm{L}, 90.4 \%$ of the peak levels reached $24 \mathrm{mg} / \mathrm{L}$. Comparable parameter estimates were obtained between the final PK model and the prospective dataset. No trend was seen in the NPDE versus time and the NPDE versus predicted concentrations. Based on the Monte Carlo simulations, peak concentrations above $24 \mathrm{mg} / \mathrm{L}$ were reached in almost all patient subgroups.

Conclusions After 14 years experience of amikacin dosing optimalisation in (pre)term neonates, a model-based dosing algorithm was prospectively validated confirming its efficacy, stability and accuracy over the entire neonatal population.

\section{0-108 PHARMACOKINETICS OF MELATONIN IN PRETERM INFANTS}

${ }^{1} \mathrm{~N}$ Merchant, ${ }^{2} \mathrm{~A}$ Hawwa, ${ }^{1} \mathrm{D}$ Azzopardi, ${ }^{3}$ I Gozar, ${ }^{3} \mathrm{~A}$ Deierl, ${ }^{1} \mathrm{~T}$ Arichi, ${ }^{1} \mathrm{~N}$ Tusor, ${ }^{4} \mathrm{~A}$ Kapetanakis, ${ }^{4} \mathrm{M}$ Sharma, ${ }^{5} \mathrm{M}$ Wan, ${ }^{1} \mathrm{P}$ Gressens, ${ }^{1} \mathrm{AD}$ Edwards. ${ }^{1}$ Centre for the Developing Brain Perinatal Imaging and Health, King's College London, London, UK; ${ }^{2}$ School of Pharmacy, Aston University, London, UK; ${ }^{3}$ Neonatology, Imperial College Healthcare NHS Trust, London, UK; ${ }^{4}$ Neonatology, Guy's and St Thomas' NHS Trust, London, UK; ${ }^{5}$ Pharmacology, Guy's and St Thomas' NHS Trust, London, UK

\subsection{6/archdischild-2014-307384.175}

Background Evidence from neonatal studies is critical in understanding developmental variations in drug pharmacokinetics and can guide dosing adjustments. Melatonin has been shown previously in a single dose study to have slow clearance and prolonged half-life in preterm infants.

Aim To determine the melatonin pharmacokinetic profile in preterm infants on exogenous supplementation and to determine the melatonin concentrations in donor and maternal breast milk. Methods The study was part of an exploratory; double-blinded randomised placebo controlled trial evaluating the neuroprotective effect of melatonin in preterm infants less than 31 weeks gestation. Infants in the melatonin $\operatorname{arm}(\mathrm{n}=29)$ received an intravenous infusion $0.1 \mathrm{mcg} / \mathrm{kg} / \mathrm{hr}$ for $2 \mathrm{~h}$ once daily for 7 days starting by $48 \mathrm{~h}$ after birth. The placebo group $(n=28)$ received same volume of saline. Plasma and milk melatonin concentrations were analysed by radioimmunoassay. Population pharmacokinetics was carried out using NONMEM.

Results The median plasma melatonin levels on day 4 was $152 \mathrm{pg} / \mathrm{ml}$ in the melatonin group and was $0 \mathrm{pg} / \mathrm{ml}$ in the saline group. On nonlinear mixed effect modelling, using first order conditional estimation with interaction, the clearance was $0.05 \mathrm{~L}$ / hr with a half-life of $15.61 \mathrm{~h}$. Effect of covariates: gender and race were not significant in this study unlike previously reported. Mean melatonin concentrations in donor breast milk were $63 \mathrm{pg} /$ $\mathrm{ml}$, higher than that of maternal breast milk even on day 4 (16.6 pg/ml).

Conclusions Preterm infants have delayed clearance and prolonged half-life of melatonin. This data can be used for simulation of future dose studies in preterm infants.

\section{0-109 NEBULIZED ADRENALINE IN 3\% HYPERTONIC SALINE SOLUTION IN BRONCHIOLITIS: IS SAFE?}

${ }^{1} \mathrm{JC}$ Flores-Gonzalez, ${ }^{1}$ B Serrano Moyano, ${ }^{1}$ RM García Ortega, ${ }^{1} \mathrm{FJ}$ Dávila Corrales, ${ }^{1} \mathrm{~J} \mathrm{~J}$ Pérez Guerrero, ' L García García, 'E Palma Zambrana, 'P Comino Vazquez, ${ }^{1} \mathrm{P}$ Rodriguez Campoy, ${ }^{1}$ MA Matamala Morillo, 'S Garofano-Montero, ${ }^{1} \mathrm{IM}$ Calvo-Morales, ${ }^{2} \mathrm{AM}$ Lechuga Sancho. ${ }^{1}$ Pediatrics Department, Hospital Universitario Puerta Del Mar, Cádiz, Spain; ${ }^{2}$ Cadiz University, Hospital Universitario Puerta Del Mar, Cádiz, Spain

\subsection{6/archdischild-2014-307384.176}

Background and aims The use of nebulized adrenaline in the treatment of infants with acute bronchiolitis, has been related to increased cardiac rate. On the other hand, bronchoconstriction episodes requiring bronchodilators have been reported with the use of nebulized $3 \%$ hypertonic saline solution $(3 \% \mathrm{SSH})$ without bronchodilators. We aimed to analyse the safety of nebulized adrenaline and nebulized 3\% HSS in the management of infants hospitalised for acute moderate bronchiolitis.

Methods Randomised, double-blind, controlled trial. 185 hospitalised infants $(2.11 \pm 2.23$ months (mean $\pm \mathrm{SD})$ received nebulized $3 \% \mathrm{HSS}(7 \mathrm{ml})$ either with $3 \mathrm{mg}$ of adrenaline (group $\mathrm{SSH} 3 \%+\mathrm{A} ; \mathrm{n}=94$ ) or $3 \mathrm{ml}$ of placebo (group SSH3\%+P; $\mathrm{n}=$ 91), in addition to routine therapy. Nebulizations were initially administered every four hours and adjusted thereafter according to clinical response. The principal outcomes measures were cardiac rate $(\mathrm{CR})$ and frequency rate (FR) up to the median of stay, nebulization requirements and need of transfer to the PICU.

Results There was not statistically significant differences in the cardiac frequency ( $p=0.76,0.48$ and 0.73 , respectively) and frequency rate $(\mathrm{p}=0.88,0.07$ and 0.24 , respectively) in 3 days of median of stay, nebulizations rates $(\mathrm{p}=0.89)$, PICU's admission $(p=1)$. No other adverse events were reported.

Conclusion In acute bronchiolitis for moderately ill hospitalised infants, nebulized adrenaline and nebulized 3\%HSS are safe.

\begin{tabular}{llllllll}
\multicolumn{7}{l}{ Abstract } & 0-109 Table 1 \\
\hline & $\mathrm{CR}(1 \mathrm{~d})$ & $\mathrm{CR}(2 \mathrm{~d})$ & $\mathrm{CR}(3 \mathrm{~d})$ & $\mathrm{FR}(1 \mathrm{~d})$ & $\mathrm{FR}(2 \mathrm{~d})$ & $\mathrm{FR}(3 \mathrm{~d})$ & $\mathrm{Neb}$ \\
$3 \% \mathrm{HHS}+\mathrm{P}$ & 143 & 143 & 142 & 49 & 49 & 48 & 4.13 \\
$3 \% \mathrm{HHS}+\mathrm{A}$ & 141 & 142 & 142 & 49 & 47 & 46 & 4.17 \\
$\mathrm{p}$ & 0.76 & 0.48 & 0.73 & 0.88 & 0.07 & 0.24 & 0.89 \\
\hline
\end{tabular}

